\title{
Household Decision-Making Process: It's Effect on School Dropout Behavior for Girls in the Secondary School Level in Bangladesh
}

\author{
S. M. Shahidul ${ }^{1}$ \\ ${ }^{1}$ Center for the Study of Social Stratification and Inequality (CSSI), Graduate School of Arts and Letters, \\ Department of Behavioral Science, Tohoku University, Sendai city, Miyagi ken, Japan \\ Correspondence: S. M. Shahidul, Center for the Study of Social Stratification and Inequality (CSSI), Graduate \\ School of Arts and Letters, Department of Behavioral Science, Tohoku University, 27-1, Kawauchi, Aoba-ku, \\ Sendai City 9808576, Miyagi Ken, Japan. Tel: 81-022-795-6011. Fax: 81-022-795-6011. E-mail: \\ mpshahidul@yahoo.com
}

\author{
Received: October 16, 2012 Accepted: November 12, 2012 Online Published: December 4, 2012 \\ doi:10.5539/ies.v6n1p132 \\ URL: http://dx.doi.org/10.5539/ies.v6n1p132
}

\begin{abstract}
This study aims to understand the parents' household decision-making process with respect to allowing girls to drop out of school, an area that has, thus far, been overlooked in the research regarding school dropouts. This paper has examined the household decision-making process between fathers and mothers and explores how their respective levels of participation affect on the educational outcome for girls. Data were collected in September 2010 from questionnaires administered to the parents of female students in the sub-district of Pirgonj in Bangladesh. The individual participation index (PI) of both the fathers and the mothers was estimated for four major household matters, and the bargaining level of fathers and mothers was measured by comparing the participation indices. Logistic regression was then conducted to examine how the participation levels of fathers and mothers predicted dropout outcomes for girls. The results show that mothers had less bargaining power than fathers in the decision-making process as the mean for the mother's participation index is found to be "rarely", while the father's index is found to be "very often" when using a 5-point Likert-typescale. In the logistic regression model, the participation levels of fathers and mothers indicate diverse effects on dropout outcomes in which the father's participation positively predicts the dropout outcome for girls and the mother's participation negatively predicts the dropout outcome for girls.
\end{abstract}

Keywords: school dropout, household decision-making, bargaining, gender bias, son preference

\section{Introduction}

The school dropout rate for girls is significantly higher than it is for boys in Bangladesh, where nearly $80 \%$ of the girls in the secondary level leave school before completing grade X (Bangladesh Education Bureau of Statistics Report, 2005.) Although the school dropout issue for girls has been explored before, the decision-making process exercised by the parents for girls to leave school early has been neglected. To determine the factors underlying why girls drop out of school, it is important to explore whether household decisions are made with or without the mother's participation in the household decision-making process, as several scholars have argued that the intra-household allocation of resources favor to male children over female children (Bardhan, 1982; Sen \& Sengupta, 1983). The unitary model (Gray Becker's model, 1981), also called the "common preference" model, is based on the notion that a single decision maker acts for the good of the entire household, and it assumes that all household resources are allocated by a household head who represents the distributor's taste and preference. As a consequence, in the male dominated society, decisions regarding the well-being of children, including their education, become gender biased, thus resulting in a situation where girls may receive less preference relative to boys by the father. Accordingly, Thomas (1994) noted that fathers prefer to invest their resources in their sons rather than their daughters. This study argues that when the mother participates with the father in the household decision-making, household decisions are less gender biased or daughters receive preference over sons. Scholars explained this phenomenon by stating that women are, on average, more altruistic and less gender biased than man (Enland \& Paula 1989).Somewhat consistent with this argument (Kruper \& Uzgiris, 1987; Lytton \& Romney, 1991) found that mothers are more likely to prefer 
daughters or are less apt to differentiate with respect to gender. (Thomas, 1994) also noted that mothers prefer to invest more resources in their daughters than in their sons.

Therefore, this study argues that the level of education attained for girls depends on whether household decisions are made with or without the input of the mothers. This paper contributes to this debate by examining the household decision-making process between fathers and mothers and how their respective levels of participation affect on the educational outcome for girls. This study considers the following four important household issues: (a) decisions regarding household expenditures, (b) decisions regarding educational matters of children, (c) decisions regarding household labor for children, (d) decisions regarding health care for children. These four factors are considered because these are strongly allied with the educational attainment of children. However, several literatures on gender preference suggest that parents have a general propensity toward a preference for sons over daughters with respect these four important household decisions, especially in developing countries. For instance, Deaton, 1988; Song, 2001) explored household expenditure patterns and found that girls are at a disadvantage relative to boys in developing countries. (Edmondsand Pavcnik, 2005) found that girls are expected to perform more household tasks than boys, a gap that grows with the preference for sons. This preference for sons is also linked with differential treatments between boys and girls when parents consider allocation of family resources with gender disparities in parental investments in children's health (Pande, 2003) and education (Connelly \& Zhang, 2003) and (Mishra, Retherford, \&Roy 2004) being well-documented in the literature

In a male-dominated society, household decisions are made, for the most part, solely by the husbands. The bargaining model on household decisions argues that the stronger the bargaining power of the family member, the greater that family member's influence on resource allocation decisions (Sen, 1990).Thus, in patriarchal societies, if women (mothers) have higher bargaining power, they are more likely to participate in the decision-making process, a factor that may be relevant when examining educational decisions for girls. However, in the patriarchal developing social settings, women are constrained by the norms, beliefs, customs and values, which limit their freedom of choice in every aspect of their lives. Accordingly, this study assumes that if mothers have strong bargaining power, then mothers are more likely to participate with their partner (husband) in making household decisions. When mothers participate, a bargaining process is employed when household decisions are made, which decreases gender bias preference (son preference) of fathers and, consequently, decreases the likelihood of daughters dropping out of school. From this perspective, this study hypothesizes that if the father's participation level in the household decision-making process increases, the school dropout rate for girls also increases. On the other hand, if the mothers' participation level in the household decision-making process increases, the school dropout rate for girls decreases. If the proposes hypotheses of this study are valid, this paper will contribute to the literature on school dropout rates.

\section{Literature Review}

This study considers the literature on the household context and school dropout behaviors of children. Several studies found that parental income and education both are the dominant predictors of schooling attainment and dropout behavior for children (Bryk \& Thum, 1989; Ekstrom et al., 1986; McNeal, 1999; Rumberger \& Larson, 1998; Pong \& Ju, 2000). Parental income is associated to a variety of factors for instances when children begin school, how often they attend, whether they have to temporarily withdraw and when, and if, they drop out (Croft, 2002). (Birdsall et al., 2005; Boyle et al. 2002) explored that children from rich families are more likely to continue the school, while those who are from disadvantaged families are more likely to drop out. The National Center for Educational Statistics (NCES) observed the relationship between household earnings and dropping out of school. High school students from household within the lowest $20 \%$ income were six times likely to dropout out of high school as are students from household in the top $20 \%$ of the income range (Blue \& Cook, 2004).

Another essential factor that is often associated to whether a child drops out of school is the level of the parents' education (Chowdhury et al., 2002; Nath et al. 2008; Blick \& Sahn, 2000; Brown \& Park, 2002) also found that parents with low levels of education are more likely to have children who do not attend school, and if the children do attend school, they are highly tended to drop out. (Ersado, 2005) examined that parental education is the foremost determinant of child education. In this regard Al Samarai \& Peasgood, (1998) also posited that higher level of parental education is allied with higher access to education, higher attending rates in school and lower school dropout rates for children. (Battin-Pearson \& Newcomb, 2000) found that lower level of parental education negatively affected the children academic attainment, which had a significant effect dropped out outcome. (Ainsworth et al., 2005; Grant \& Hallman, 2006) argued that parents tend to provide the education to children at least the same level of own education. 
(Grant \& Hallman's, 2006) research on educational access in South Africa determined that children those lived with mothers were less likely to dropout. In another study on South Africa, (Hunter \& May, 2003) described the association between students' family background and dropping out outcome. Here, children from single-parent and poor families and with lower educated parents were more likely to school dropout early. The number of children in the family is also an important factor of dropout rates (Boyle et al., 2002: 4). Regarding the household size some studies examine that children in large household size are more likely to the financial burden and workload which lead them to drop out from education (Colclough et al., 2000). In other studies observed that the number of siblings under 5years of age in the family has a negative impact on older girls' schooling which consequent the dropout (Glick \& Sahn., 2000). Moreover, some household factors such as low educational levels of household members, birth order of children also influence dropout rates (Leka \& Dessie, 1994 cited in Nekatibeb, 2002; Odaga \& Heneveld, 1995 in Nekatibeb, 2002).

Although studies on the school dropout issue have been enlightened in many ways however, most of the prior studies have been performed regardless the gender of the children and less pursued to determine the underlying causes of dropout which affecting especially for girl children. In terms of household contexts, a number of factors affect educational access and the potential to dropout, there is no clear understanding of how the household decision for girls to drop out of school is reached by the parents. On the other hand, several studies on gender preference show that the influence of fathers and mothers on the well-being of children differs by genders of both the children and the parents in the household (e.g., Thomas, 1994; Kruper \& Uzgiris, 1987; Lytton \& Romney (1991)). Therefore, it is important to explore how fathers and mothers participate in the household decision-making process to find the underlying factor that influences the decision for girls to dropout of school.

\section{Influences on Household Decision-making Process}

This section identifies which factors affect the bargaining power of decision making as several factors impact the family/household decision making process. Figure 1 identifies some these factors.

\begin{tabular}{|l|l|}
\hline Degree of gender-role disparity & \\
$\begin{array}{l}\text { Degree of tangible resource disparity } \\
\text { Degree of intangible resource } \\
\text { disparity }\end{array}$ & $\begin{array}{l}\text { Decision-making process regarding } \\
\text { internal and external family-related } \\
\text { behaviors }\end{array}$ \\
\hline
\end{tabular}

Figure 1. A partial model of family decision making (Source: By J Scanzoni, \& M Szinovacz, 1980)

\subsection{Degree of Gender-role Disparity}

(Blalock \& Wilken, 1978) interpreted the "subjective utilities" by measuring the variation of preferences between married men and women and demonstrated that women and men vary on the degree to which they do or do not prefer specific tastes, utilities, interests and so forth. They identified certain items to develop an index of preferences regarding the roles of wife, husband, mother and father. The variations were generally measured by Likert-type responses (strongly agree, agree, mixed feelings, disagree, and strongly disagree) to the items. One item regarding the role of wife was, "A married women's most important task in life should be taking care of her husband".'(Scanzoni \& Szinovacz, 1980) developed this item to measure how traditional or modern the individual's attitude regarding the role of the wife is. A person who responded that she or he "strongly agreed" with this item was labeled strongly traditional because that individual accepts the idea that a women's chief task in life is to devote herself to her husband. On the contrary, those who responded with "strongly disagree" were labeled as strongly modern or egalitarian because he/she rejects the idea of that the female should be completely devoted to providing for her husband's needs. The authors measured (using a Celsius scale) the degree of sex role disparity by comparing these two responses and argued that the degree of traditionalism-modernity held by each spouse with respect to the role of the wife affects the household decision making process.

\subsection{Degree of Tangible Resources Disparity}

The tangible resources behind family decisions (Cromwell \& Olson 1975; Burr, 1973) refer to certain background factors such as educational level, employment status and income level of the individual. (Blood \&Wolf, 1960) determined that if the husbands have more of each of these resources, the wife is more likely to acquiesce and allow the husband to make the decisions regarding household matters always or most of the time. This finding suggests the degree of power the husband has, while the significance of these resources implies the disparity between the husband and wife. In this respect (Scanzoni \& Szinovacz, 1980)) demonstrated an example 
where there are two husbands, each of whomearns $\$ 15,000$ per year. If the wife of the first husband earns $\$ 13,000$ and the wife of the second husbandearns $\$ 6,000$, the impact on the decision-making process is accorded to the disparity of income between the wives. Similarly, if one spouse has 11 years of schooling and the other has 15 years of education, this 4 year disparity is likely to have an impact on the household decision-making process. Additionally, if one spouse is a semiprofessional but married to a professional, then the disparity between them is much less than if the professional were married to a factory worker. Thus, the greater the job-status disparity, as with education and income disparity, the greater the impact on the household decision-making process.

\subsection{Degree of Intangible Resource Disparity}

Self-esteem is an individual characteristic, and as such, scholars of the family decision making process are interested in determining the impact that the self-esteem has on the decision-making process with respect to the partner's involvement in that process. (Scanzoni \& Szinovacz, 1980) stated that self-concept is learned through certain social situations and that in some situations a person's self-image is higher than it is in other situations. They also stated that self-esteem is a benefit and a resource that helps and enhances its possessor similar to the way that tangible resources do. Therefore, self-esteem disparity is likely to affect decisions analogous to that of tangible resources. For instance, some studies have indicated that women tend to possess a lower self-concept than men, and therefore, women tend to think less of themselves (Simmons \& Rosenberg, 1975; Simons et al., 1979). Accordingly, self-esteem disparity exists between the husband and wife. In this regard, a study on negotiation philosophy by (Scanzoni, 1978) found that certain measures of self-worth and self-evaluation were positively related to sex-role egalitarianism. Consequently, self-esteem disparity is connected to the ways in which partners actually perform in the decision-making process. Thus, where there is no self-concept disparity and husbands and wives consider themselves equal, wives are more likely to behave in identical ways to their husbands in the household decision-making process. Where there is a self-esteem disparity, however, husbands tend to have a better self image than wives, and husbands are more likely to persist in the household decision-making process, which may benefit the husband's interest more so than the wife's interest.

\section{Methods}

\subsection{Data and Measurement of Variables}

This study was carried out in one the town zone of the sub-district namely Pirgonj Upazila of Rangpur District in Bangladesh 2010. There are 5 secondary schools in the town zone at Pirgonj and all the schools were used as source of data. The town zone of this sub-district was chosen to obtain a more heterogeneous pool of respondents; given that this study concentrated on students' family background characteristics and those student compositions were more heterogeneous in schools located in this region. The Pirgonj sub-district was also chosen to obtain a more heterogeneous sample because "regional imbalances continue to exist in Bangladesh" (Islam, 19979). Pirgonj has an average literacy rate of $26.5 \%$ ( $7+$ years), while in nearby areas, the national average is $32.4 \%$. To avoid unexpected deviations in the sample, Pirgonj was selected as a sampling area. Parents of girls' students were used as respondents of this study. This study included data from 268 parents, 69\% (185) of whom were parents of non-dropout girls and 31\% (83) of who were parents of dropout girls. Questionnaires were used to collect information about participants' socio-demographic characteristics and their level of participation in household decision making through face-to-face interviews. Dropout status measured as dummy in where dropout $=1$, and non dropout $=0$ indicated in this study.

\subsection{Participation in Household Decision-making}

Fathers and mothers were asked separately to respond to the questions: "How much you participate when the following household decisions are made?"There are four household issues included as part of the survey: (a) decisions on household expenditures, (b) decisions on educational matters regarding the children, (c) decisions on household labor regarding the children, (d) decisions regarding health care for the children. All of the responses were measured using a 5-point Likert scale where 1 represents never participate, 2rarely participate, 3 sometimes participate, 4 very often participate and 5 always participate. Participants who make decisions completely alone are treated as a 5 - always participate. A range of measurement techniques has been used in a series of decision-making arenas by scholars world-wide, and the level of participation was measured by Rahman and Rao (2004) in two ways, using a categorical measurement and using index scores. Casique (2001) measured domestic decision-making by adding all sub-items. From this perspective, a participation index (PI) was estimated by adding the values of all 4 items for each participant. Thus, the PI of one participant could range from 4 to 20 (as 4 iteams are measured using a 5-point Likert scale). 


\subsection{Background Variables}

The educational levels of both the fathers' and mothers' education level were measured using total years of education completed, and income level was measured based on the total monthly income. With respect to father's employment status, fathers employed in the agricultural, farming or self-finance business sectors are considered to be self-employed while fathers employed in an office or an institutional setting are considered to have employee status. With respect to the mother's employment status, mothers who are living in the house and caring for the family are considered housewives, while mothers who are employed in an office or an institutional setting are considered to have employee status.

\subsection{Analytical Method}

With respect to decision-making strategies, the bargaining model explores the relationship between bargaining and power within the household, which is called the fallback position (also termed the "threat point") of decision makers. Inequality to fallback positions within the decision maker creates a situation where individuals have more or less bargaining power and, therefore, have more or less influence over household decisions. (Sen, 1990) also found that the stronger the bargaining power the individual has, the greater the influence on household resource allocation decisions. The bargaining model considers the factors that determine the bargaining power or fallback position of decision makers, and the foremost determinants of bargaining power are education and income of the individuals. (Cromwell \& Olson, 1975; Bur, 1973) considered certain background factors such as education and income level of the individual as the tangible resources of family decisions. (Blood \&Wolf, 1960) and many other studies determined that if the husbands have more of each of these resources, the more likely the wife is to say that the husband decides the household matters always or more often than she. This finding indicates the degree of power the husband has, while the significance of these resources imply the disparity between the husband and wife. From this perspective, this study compares the education and income level of fathers and mothers to determine whether the fathers or the mothers have greater decision-making power. Accordingly, the partner who has more education and earns more income has more bargaining power or a higher threat point in the household decision making process. This study also compares the participation quality between fathers and mothers to determine whether the fathers or mothers have a higher participation level in making household decisions. The mean of the PI education and income levels of fathers and mothers has been calculated for comparison purposes. The study further conducted a logistic regression model to determine the outcome of participation quality in the decision-making process of fathers and mothers with respect to the educational attainment of girls. A logistic regression analysis was conducted with the dependent variable (dropout) as a dichotomy variable. The model measures the effects of fathers and mothers participation levels in the household decision-making process on the school dropout outcome for females.

\section{Results}

The results in table 1 show that the mean of the fathers' participation index (PI) is 4 , which indicates that fathers "very often participate", while the mothers' participation index (PI) is 2, which indicates that mothers "rarely participated". Thus, the results confirm that mothers participate less than fathers in making household decisions. With respect to the level of education, results show that fathers and mothers have an average of 12 years and 5 years of education, respectively. Finally, with respect to income level, fathers and mothers earn an average of 14 thousand and 6 thousand (BDT), respectively. Thus, fathers have more education and earn more money than mothers. Accordingly, these results show that fathers have greater bargaining power than mothers when making household decisions.

Table 1. This table implies the comparisons of participation index in household decisions making and bargaining power by measuring the education and income level between fathers and mothers in Bangladesh

\begin{tabular}{lrr}
\hline Variables & Fathers (mean) & Mothers (mean) \\
\hline Participation Index & 4 & 2 \\
Education Level & 12 (years) & 5 (years) \\
Income Level & 14 thousand(BDT) & 6 thousand(BDT) \\
\hline
\end{tabular}

$\mathrm{N}=268$ (fathers), 268 (mothers) 
The results in table 2 reflect the maximum likelihood estimation of the logit model. The Chi-square method was used to determine the fit of the data. The higher Chi-square statistics indicate that model three is highly significant as $P<0.0001$.

Table 2. Logistic regression model on school dropout behavior for girls in Bangladesh

\begin{tabular}{|c|c|c|c|}
\hline & Model- 1 & Model- 2 & Model -3 \\
\hline \multirow[t]{2}{*}{ Dependent variable $=$ Dropout } & $\beta(\mathrm{SE})$ & $\beta(\mathrm{SE})$ & $\beta(\mathrm{SE})$ \\
\hline & $8.34 * *$ & $7.11 * *$ & $6.31 * * *$ \\
\hline \multirow[t]{2}{*}{ Constant } & $(1.12)$ & $(0.45)$ & $(0.44)$ \\
\hline & $2.22 * *$ & $2.45 * *$ & $3.14 * * *$ \\
\hline \multirow[t]{2}{*}{ Fathers' PI } & $(0.12)$ & $(0.31)$ & $(0.33)$ \\
\hline & $-2.43 * *$ & $-2.02 * *$ & $1.64 * * *$ \\
\hline \multirow[t]{2}{*}{ Mothers' PI } & $(0.22)$ & $(0.34)$ & $(0.11)$ \\
\hline & & $-2.32 * * *$ & $-1.56^{* * *}$ \\
\hline \multirow[t]{2}{*}{ Fathers' Education } & & $(0.41)$ & $(0.15)$ \\
\hline & & $-1.62 * *$ & $-1.05 * * *$ \\
\hline Fathers' Income & & $(0.17)$ & $(0.16)$ \\
\hline $\begin{array}{l}\text { Fathers' Employment Status (dummy) } \\
\text { Self-Emplovee (reference) }\end{array}$ & & $-3.03 * *$ & $-2.41 * * *$ \\
\hline \multirow[t]{2}{*}{ Employee } & & $(0.11)$ & $(0.03)$ \\
\hline & & & $-1.44 * * *$ \\
\hline \multirow[t]{2}{*}{ Mothers' Education } & & & $(0.03)$ \\
\hline & & & $-1.15^{* * *}$ \\
\hline Mothers' Income & & & $(0.13)$ \\
\hline Mothers' Employment Status (dummy) & & & \\
\hline Housewife (reference) & & & $-1.00^{6}$ \\
\hline Employee & & & $(0.04)$ \\
\hline
\end{tabular}

$P^{* *}<.01, P^{* * *}<.001 . \quad \chi 2=391.21(5), P<0.0001$.

$R^{2}=$ (Negelkar), $0.26,0.34,0.41$

All the variables are significant to at least the 5\% level in the model. The robustness of the most statistically significant variables are most important in this study (fathers' and mothers' participant index) and are further verified by the minimal change in the coefficient values that occurred after controlling the background variables (education, income and occupation status of fathers and mothers) in model three. This study shows that fathers' participation index significantly $(\mathrm{p}<.001)$ and positively affects the dropout outcome of girls. That is, a one unit increase in the fathers' participation in household decision making increase the likelihood of a girl dropping out by $3.14 \%$. Therefore, the hypothesis regarding the fathers' participation level holds. In other words, an increase in the participation level of the father in making household decisions results in an increase in the likelihood that the daughter will drop out of school. On the other hand, the mothers' participation index significantly $(\mathrm{p}<.001)$ and negatively affects the dropout outcome. This finding means that a one unit increase in the mother's level of participation in making household decisions decreases the likelihood of the daughter dropping out by $1.64 \%$. Therefore, the hypothesis regarding the mothers' level of participation holds. Accordingly, if the level of the mother's participation in making household decisions increases, the likelihood that the daughter will drop out of school decreases. Other background variables such as the education and income levels of both fathers and mothers similarly (negatively) impact the dropout outcome. With respect to employment status, girls whose fathers have employee status are less likely to dropout than girls whose fathers have self-employee status. When 
employee status is used as a dummy variable, the result is a significant negative coefficient (- 3.03). Similarly, with respect to mothers' employment status, girls whose mothers have employee status are less likely to dropout than girls whose mothers have housewife status. When employee status is used as dummy variable, a significant negative coefficient (-1.06) is obtained.

\section{Discussion and Conclusion}

Household decisions are made primarily by the fathers in Bangladesh, as the results show that mothers are less likely to participate in the household decision-making process than the fathers. Furthermore, results of the logistic model show that fathers' participation positively predicts the dropout outcome for females, indicating that household decisions reflect preferential consideration for the well-being of the sons rather than the daughters when the decisions are made by fathers. In the South Asian traditional societies, including Bangladesh, greater emphasis is awarded to sons rather than daughters for a variety of social and economic reasons. There are two primary reasons that sons receive preference in these cultures. The first is related to the fact that many of these societies are Patrilineal, where only men can continue the family lineage as women leave their own parents' homes and are absorbed into the husband's lineage after marriage.

The second reason is related to the "instrumental" value of sons, or more broadly, a number of economic factors that influence son preference. Moreover, these economic factors are, themselves, culturally constructed because they result from the logic of the kinship system. The question of elderly support is a good example of how kinship systems create economic incentives for son preference. In South Asian societies, when parents reach old-age, they typically live with their married children, and these are overwhelmingly sons. In these societies, sons are perceived to be better providers and better able to support their elderly parents than daughters because the daughter moves in with her husband's family when she gets married, and she thus cannot look after her own parents when they grow old. It is commonly argued that parents prefer sons because their perceived net value is higher than that of daughters. For example, as labor market opportunities for women have remained more constrained worldwide, this inequality is even greater in developing country. Moreover, the earning potential of men is higher than that of women in most countries, regardless of their qualifications (Rosenzweig \& Schultz, 1982; Kishor,1993; Berik \& Biglinsoy, 2000; Bahttacharya, 2005), and if women's earnings do increase, this benefit goes to the husband's families, not to the parents of the daughters. Therefore, parents have an increased reason to build up their sons' resource capital, as sons are expected to generate income for the family in the future.

Many studies on son preference provide evidence that parents tend to prefer sons to daughters. However, the results of this study indicate that fathers and mothers have diverse effects on the schooling outcome for girls. In the logistic model, the mothers' level of participation in the household decision-making negatively affects school dropout outcome, which implies that the mothers' participation in making decisions reduces the likelihood that their daughters will dropout because mothers either prefer daughters or they demonstrate amore altruistic preference than do fathers regardless of the gender of the children. The literature, as well as this study, suggests that mothers are more altruistic than fathers (e.g., Enland \& Paula 1989). There are many reasons why mothers tend to be more altruistic regardless of the gender of the children in the household. Asian societies are typically male dominated, a fact that is especially true in the South Asian societies where most of the households are provided for by a single earner, the father. Accordingly, fathers are responsible for providing all of the financial necessities of the household members, while the mothers live as dependents of their husbands. In this situation, fathers may feel anxious when they consider their future old age. However, mothers are not worried about their future life, as their husbands (fathers of children) are responsible for supporting them in the present and the future. Consequently, mothers do not separate or show preference to one gender over the other because it does not impact their future to the degree that it impacts the fathers' future.

Another reason for the altruism of mothers is reflected in their levels of education and income. Mothers with an individual income feel more secure about their future old age than do mothers with no income. Educated mothers are more conscious about the future success of their children and try to promote the well-being and success of their daughters because women are so often neglected by society in general. Thus, the mothers' altruism or preference for daughters is important for the daughters' educational attainment when fathers have a propensity to favor the sons. However, despite the mothers' altruism, they usually cannot act upon it, as they have no autonomy or power in the household decisions. When mothers have no income or make no financial contribution to the household income, they do not even autonomy to bargain with their partners regarding household decisions. 
Gender inequality is a serious concern in developing patriarchal societies in Bangladesh where women suffer inequalities and lack authority in the household decision-making process, thus allowing the males to make all major decisions and control all valued resources, in general. Women are often constrained by the traditional norms and beliefs in these South Asian patriarchal societies. For instance, traditional women in these cultures who have no education believe that men always make the proper decisions and the wife should not argue with or contradict their husbands. Females should not attain a higher level of education than males, and women should not work outside the home. In fact, women's marginalization begins at infancy and continues thereafter, and it, in fact, pervades their society and is reflected in women's low self-esteem and powerlessness. The norms and cultures of these societies inhibit women's involvement in market transactions and curb their potential to generate income, thus reinforcing their economic dependence on men (Hashemi et al.,1996).Women encounter many unpleasant experiences including economic deprivation and a lack of freedom of choice in every aspect their lives. As a result, the decision-making power and the ability of women to participate in household activities are reduced. The results of the participation index in this study indicate that mothers participate less in the household decision-making process, they have less education and lower income levels than the fathers. Thus, the results of this study suggest that mothers have less bargaining power and participate less in the household decision-making process.

Therefore, based on the results of this study and according to the bargaining theory, it can be concluded that household decisions in Bangladesh are made by the fathers who discourage the girls from attaining an education. Consequently, the rate of female enrollment especially at the secondary school level is still significantly lower than that of male enrollment. Girls are becoming more likely to dropout from school than boys. The foremost reason for this is gender discrimination by fathers in the male dominated society of Bangladesh.

\section{Acknowledgements}

The author is grateful to the "Center for the Study of Social Stratification and Inequality (CSSI)" to get all the supports including financial to perform the research project. Author is also grateful to Professor Yoshimich Sato, Director of CSSI, School of arts\& letters, Tohoku University for his kind supervisory in this study.

\section{References}

Ainsworth, M., Beegle, K., \& Koda, G. (2005). The Impact of Adult Mortality and Parental Deaths on Primary Schooling in North-Western Tanzania. The Journal of Developmental Studies, 41(3), 412-439. http://dx.doi.org/10.1080/0022038042000313318

Battin, P., \& Newcomb. (2000). Catalano, Richard F. Hawkins, J. David. "Predictors of Early High School Dropout: A Test of Five Theories." Journal of Educational Psychology. 92(3), 568-582. http://dx.doi.org/10.1037//0022-0663,92.3.568

Berik, G. U., \& Biglinsoy, C. (2000). Type of Work Matters: Women's Labor Force Participation and the Child Sex Ratio in Turkey. World Development, 28(5), 861-878.

Bhattacharya, P. C. (2006). Economic Development, Gender Inequality, and Demographic Outcomes: Evidence from India. Population and Development Review. 32(2), 263-292.

Blalock, \& Wilken. (1979). Intergroup process: A Micro-Macro perspective. New York: Free press.

Blick, P., \& Sahn, D. E. (2000). Schooling of girls and boys in a West African country: the effects of parental education, income, and household structure. Economics of Education Review, 19(1), 63-87.

Blood, \& Wolf. (1960). Husbands and Wives: The Dynamics of Married Living. New York: Free press.

Boyle, S., Brock, A., Mace, J., \& Sibbons, M. (2002). Reaching the Poor: The 'Costs'of Sending Children to School. Synthesis Report. London: DFID.

Brown, P. H., \& Park, A. (2002). Education and poverty in rural China. Economics of Education Review, 21, 523-541.

Bryk, A. S., \& Thum, Y. M. (1989). The effects of high school organization on dropping out: An exploratory investigation. American Educational Research Journal, 26(3), 353-383. http://dx.doi.org/10.3102/00028312026003353

Burr, W. R. (1973). Theory Construction and the Sociology of the Family. New York: John Wiley.

Chowdhury, A. M. R., Nath, S. R., Choudhury, R. K., \& Ahmed, M. (2002). Renewed Hope Daunting Challenges: State of Primary Education in Bangladesh, Education Watch 2001, The University Press Limited. 
Colclough, C., Rose, P., \& Tembon, M. (2000). Gender inequalities in Primary Schooling: The Roles of Poverty and adverse Cultural Practice. International Journal of Educational Development, 20(1), 5-27.

Connelly, R., \& Zheng, Z. (2003). "Determinants of school enrollment and completion of 10 to 18 year olds in China. Economics of Education Review, 22(4), 379-388. http://dx.doi.org/10.1016/s0272-7757(02)00058-4

Croft, A. (2002). Pedagogy in School Context: An intercultural study of the quality of learning, teaching and teacher education in lower primary classes in Southern Malawi. Unpublished DPhil thesis. Brighton: University of Sussex, 40(3), 337-349.

Cromwell, \& Olson. (1975). Power in Families. New York: John Wiley Deaton, Angus (1988). 'The allocation of goods within the household: adults, children and gender', LSMS Working Paper 0253-4517, No. 39, World Bank.

Edmonds, E. V., \& Pavcnik, N. (2005). Child Labor in the Global Economy. Journal of Economic Perspectives, 19(1), 199-220.

Ekstrom, R. B., Goertz, M. E., Pollack, J. M., \& Rock, D. A. (1986). Who drops out of high school and why? Findings from a national study. Teachers College Record, 87, 356-373.

England, P. (1989). "A Feminist Critique of Rational-Choice Theories: Implications for Sociology." The American Sociologist Spring, 20(1), 14-28.

Ersado. (2005). Child labor and schooling decision in Urban and Rural areas: Comparative evidence from Nepal, Peru and ZImbabue. World development, 33(3), 455-480.

Glick, P., \& Sahn, D. E. (2000). Schooling of girls and boys in a West African country: the effects of parental education, income, and household structure. Economics of Education Review, 19(4), 63-87.

Grant, M., \& Hallman, K. (2006). Pregnancy Related School Dropout and Prior School Performance in South Africa. Policy Research Division Working Paper, 212. New York: Population Council.

Gray B, S. (1965). A theory of the Allocation of time. Economic Journal, 75(299), 493-517.

Gray Becker, S. (1981). A treatise on the family, Cambridge Harvard University Press, Cambridge.

Hashemi, S. M., S.R. Schuler, \& A. P. Riles. (1996). Rural credit programs and women's empowerment in Bangladesh. World Development, 24(4), 635-53.

Hunter, N., \& May, J. (2003). Poverty, Shocks and School Disruption Episodes among Adolescents in South Africa. CSDS Working Paper, No. 35.

Kishor, S. (1993). May God Give Sons to All: Gender and Child Mortality in India? American Sociological Review, 58(2), 245-265.

Kruper, J. C., \& Uzgiris, I. C. (1987). Fathers' and mothers' speech to young infants. Journal of Psycholinguistic Research, 16(6), 597-614.

Lytton, H., \& Romney, D. M. (1991). Parents' differential socialization of boys and girls: A meta-analysis. Psychological Bulletin, 109(19), 267-296.

McNeal, R. B. (1999). Parental involvement as social capital: Differential effectiveness on science achievement, truancy, and dropping out. Social Forces, 78(1), 117-144 .

Mishra, V., Roy, T. K., \& Retherford, R. D. (2004). "Sex Differentials in Childhood Feeding, Health Care, and Nutritional Status in India." Population and Development Review, 30(2), 269-295.

Nekatibeb, T. (2002). Low participation of female students in primary education: A case study of drop outs from the Amhara and Oromia Regional States in Ethiopia. Addis Ababa: UNESCO.

Pande, R. (2003). Selective Gender Differences in Childhood Nutrition and Immunization in Rural India: The Role of Siblings. Demography, 40(3), 395-418.

Rosenzweig, M. R., \& Schultz, T. P. (1982). Market Opportunities, Genetic Endowments, and Intrafamily Resource Distribution: Child Survival in Rural India. American Economic Review, 72(4), 803-815.

Rumberger, R. W., \& Larson, K. A. (1998). Student mobility and the increased risk of high school dropout. American Journal of Education, 107(1), 1-35.

Scanzoni, J. (1978). Sex Roles, Women's Work and Marital Conflict: A Study of Family Change. Lexington, MA: D.C. Health / Lexinton Books. 
Scanzoni, J., \& Szinovacz M. (1980). Family Decision-Making. A developmental sex role model. Sage Library of Social Research, 111, 28.

Sen, A. K. (1990). Gender and Cooperative Conflicts. In Persistent Inequalities, edited by Irene Tinker, 123-149. New York: Oxford University Press.

Sen, A., \& S. Sengupta. (1983). "Malnutrition of Rural Indian Children and the Sex Bias", Economic and Political Weekly, 855-64.

Simmons, \& Rosenberg. (1975). "Sex-role and self-image". Journal of Youth and Adolescence, 4(3), 229-258.

Simons et al.. (1979). "Entry into early adolescence: The impact of School structure, puberty, and early dating on self-esteem." American Sociological Review, 44(6), 948-967.

Song, L. (2001). 'Gender effects on household resource allocation in rural China', in Carl Riskin, Zhao Renwei and Li Shi (Eds), China's Retreat from Equality. Income Distribution and Economic Transition, Armonk, New York: M. E. Sharpe: 276-302.

Thomas, D. (1994). Like Father, Like Son; Like Mother, Like Daughter: Parental Resources and Child Height. Journal of Human Resources, 29(4), 950-988. 